\title{
The New Zealand rugby injury and performance project. III. Anthropometric and physical performance characteristics of players
}

\author{
K L Quarrie*, P Handcockt, A E Waller‡, D J Chalmers*, M J Toomeyg, B D Wilsont \\ University of Otago, Dunedin, New Zealand: ${ }^{*}$ Injury Prevention Research Unit, Department of Preventive and \\ Social Medicine, Medical School; + School of Physical Education; g Human Performance Centre, School of \\ Physical Education; $\neq$ University of North Carolina at Chapel Hill, North Carolina, USA: Department of \\ Emergency Medicine, School of Medicine.
}

\begin{abstract}
Objective - To investigate the anthropometric and physical performance characteristics of New Zealand rugby players of different ages and both sexes.

Methods - 356 rugby players (264 male, 92 female) took part in the study during a single season. Playing grade ranged from schoolboys and schoolgirls to senior men and women. Assessment of height, weight, neck circumference, and somatotype was performed before the competitive rugby season. A battery of six physical performance assessments was completed after the anthropometry. Analysis of variance was used to examine differences in these variables between field positions and grades.

Results-Significant differences between forwards and backs on anthropometric and physical performance variables were apparent at all grades assessed. In terms of anthropometric characteristics, forwards of a given grade were generally taller, possessed greater body mass, and were more endomorphic and less ectomorphic than backs of the same grade. The backs tended to perform better on physical performance measures than forwards, being more aerobically fit, faster, more agile, and possessing a higher degree of muscular endurance. Differences in anthropometry and physical performance attributes were also apparent between players from the various grades. The players at higher levels were generally larger, and performed better on tests of physical performance than the players at lower levels. These differences were found in both sexes.

Conclusions - The greater body mass of the forwards allows them to obtain greater momentum than the backs when sprinting. The ability to obtain greater momentum is important in the body contact phases of the game. Forwards may compromise their aerobic fitness and speed to some extent in order to maintain a high body mass. The anthropometric and physical performance characteristics of players appear to reflect the demands placed on them by the sport.
\end{abstract}

(Br J Sports Med 1995; 29 : 263-270)

Keywords: rugby; anthropometry; physical performance; fitness

Ken Quarrie, Rugby injury and performance project, Injury Prevention Research Unit, Department of Preventive and Social Medicine, Medical School, University of Otago, PO Box 913, Dunedin, New Zealand
Rugby is regarded as New Zealand's national sport, because of the large number of participants, the success of the international team (the All Blacks), and the high media profile the sport enjoys. It is widely accepted that coaches and selectors place a high priority on size and physique when choosing players, yet there have been few attempts to describe the anthropometric and physical attributes of New Zealand rugby players.

In New Zealand, the sport is played at various levels. Rugby at club level usually involves teams within geographical areas (towns, suburbs, or rural districts) playing competitively against each other. Club rugby is subdivided into numerous grades, with senior $A$ being the highest, then senior $B$, and senior reserve. There are other grades of a social nature at the senior level. Below senior level grades are usually based upon the player's age (under-21, under-19, etc). Although the sport is played by both males and females, males represent the vast majority of players.

A summary of the anthropometric characteristics of rugby players in other reports is given in Table $1 . \cdot^{1-15}$ As can be seen, most evaluations of the anthropometric characteristics of rugby players are descriptions of one or two teams from a given grade, largely precluding useful comparisons across grades. Describing attributes which are typical of players at various grades may help identify those factors important to successful performance.

Somatotypic descriptions of French, Italian, and South African rugby players have identified forwards as being generally more endo-mesomorphic than backs. ${ }^{2,3,5}$ Other studies, however, have failed to detect such differences. ${ }^{7}{ }^{8}$ In fact, Rigg and Reilly ${ }^{8}$ reported that the most consistent anthropometric differences between forwards and backs were in terms of body size (height and body mass), rather than type of physique (measured by somatotype).

Descriptive studies detailing the physical characteristics of female rugby players have found that forwards tend to be heavier and to rate higher on endomorphy and mesomorphy, and lower on ectomorphy, than backs. ${ }^{12-14}$ In contrast to male players, 
Anthropometry and physical performance in rugby: K L Quarrie et al.

Table 1. Anthropometric characteristics of rugby players*

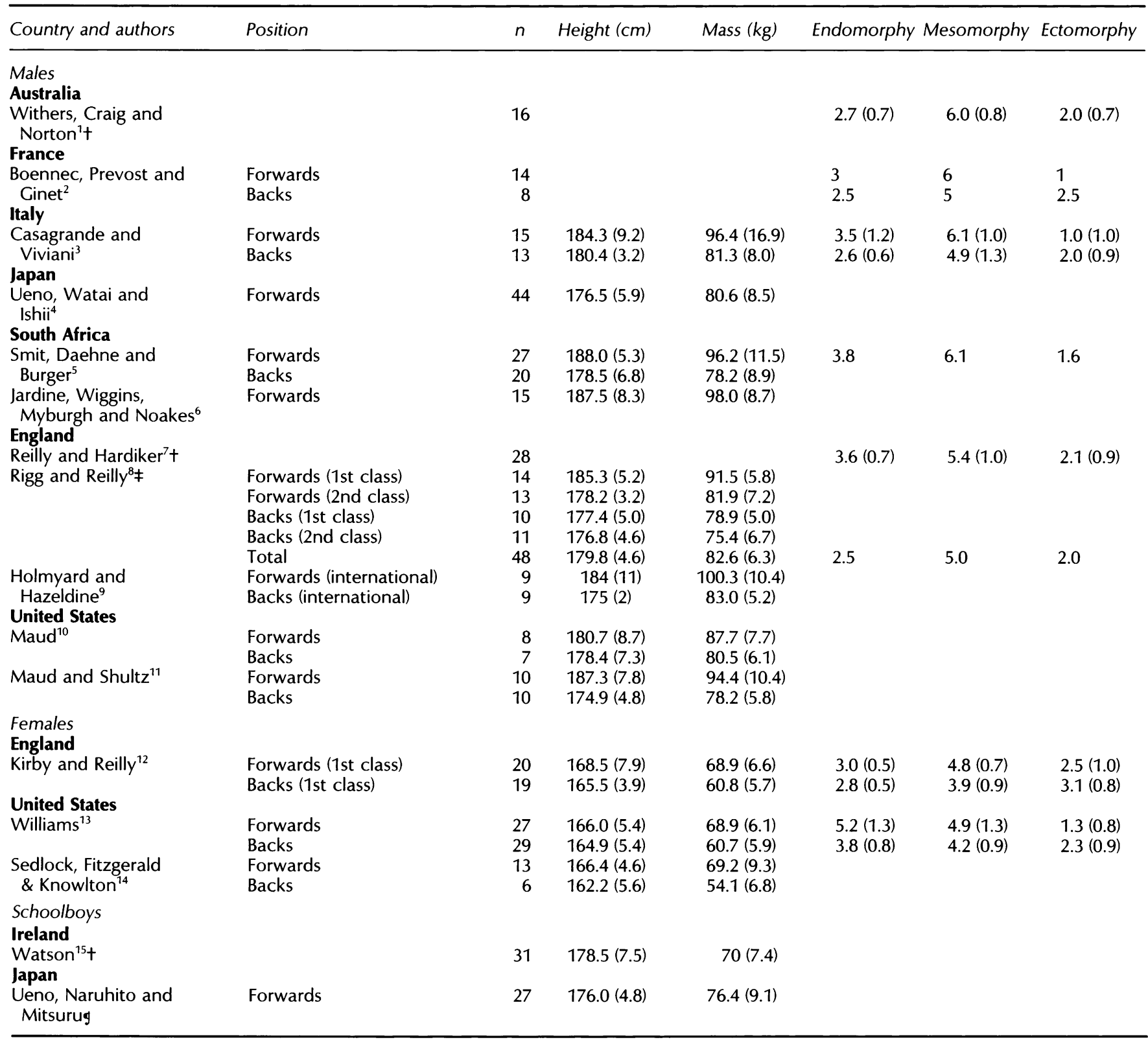

* Data are presented as mean (SD)

+ Data from forwards and backs

₹ Values derived from paper

g Unpublished data

previous comparisons between female forwards and backs indicate that they do not differ significantly in terms of height. ${ }^{12,}{ }^{14}$

Despite time and motion analyses of the rugby game $^{10,17}$ attempts to quantify the metabolic demands of the sport have been inconclusive. Many factors exert an influence on the patterns of activity during play. These include environmental conditions, fitness, level of play, officiating styles, and tactics. In view of the uncertainty surrounding the physiological requirements of the game, it comes as no surprise that a wide variety of performance tests has been used to measure the fitness characteristics of rugby players. ${ }^{6,8}, 10-12,14,18$ Unfortunately, the broad range of tests used makes it difficult to compare the performance norms of rugby players between studies.
Rigg and Reilly ${ }^{8}$ compared players from different grades on a variety of physical tests. Significant differences between grades were apparent on some of the physical performance measures. First class front row forwards, halfbacks, and backs completed significantly more push-ups than their respective peers from the second class. First class locks and loose forwards performed significantly than did their respective second class peers on a vertical jump test. No differences in sprinting speed over 40 metres were found between first class players from a given positional group and their second class counterparts.

A study of US female college rugby players reported that forwards performed significantly better than backs in terms of anaerobic power output (measured on a cycle ergometer), but no significant differences were 
observed on an agility run, or for $\mathrm{VO}_{2 \max }$ (corrected for body mass). It was suggested by the authors ${ }^{14}$ that the similarities observed in performance could in part be attributed to the similarity of the training programmes followed by the different positional groups.

The purpose of this paper is to document the size, shape, and physical performance characteristics of a cohort of New Zealand rugby players drawn from various grades, and to make comparisons between grades and positional categories.

\section{Methods}

The overall methodology used in the rugby injury and performance project (RIPP) has been described in an earlier paper. ${ }^{19}$ During the preseason club training period before the 1993 rugby season, 356 rugby union players were enrolled in the RIPP cohort. Players were recruited through five clubs and four secondary schools in the Dunedin area. Male players were drawn from the following grades: senior A, senior B, under-21, under19 , and under-18. For the purposes of this paper, the players from the under-19 and under-18 grades were grouped together. Female players were drawn from the senior women and schoolgirl grades. Cohort members attended a preseason assessment during which they completed a questionnaire and a series of physical performance assessments. Anthropometric measures were also taken. Seven players were unable to take part in any of the physical performance assessments because of injury or illness, five were in grades other than those listed above, and position was not known for one player. A total of 343 players ( 252 male, 91 female) was therefore eligible for inclusion in the analyses.

The anthropometric and physical performance assessments were conducted by a group of 10 assessors. The assessors were trained in anthropometric assessment techniques by two experienced anthropometrists. Interand intratester reliability was evaluated over an extended training period which included two pilot testing sessions (one group of 20 subjects and one group of 30). The assessments of the players were carried out before the competitive rugby season. The anthropometric assessments taken were height, body mass, neck circumference, and the measurements required for calculating the somatotype according to the methods outlined by Carter and Heath. ${ }^{20}$

Following the anthropometric assessments, a battery of six physical performance assessments was undertaken. These were administered in the following order:

(1) The 20 metre multistage shuttle run test ${ }^{21}$ was used to gauge aerobic performance. This test is widely used for assessment of the aerobic fitness of rugby players in New Zealand and appears to be an appropriate and reliable measure. The number of shuttles completed by each player was recorded.

(2) Vertical jump height was measured using a modified Sargent vertical jump test. ${ }^{22}$ A countermovement jump for maximum vertical jump height was measured using an ultrasonic jump tester (Lafayette model 01100 Vertisonic jump tester). The best of three attempts was recorded.

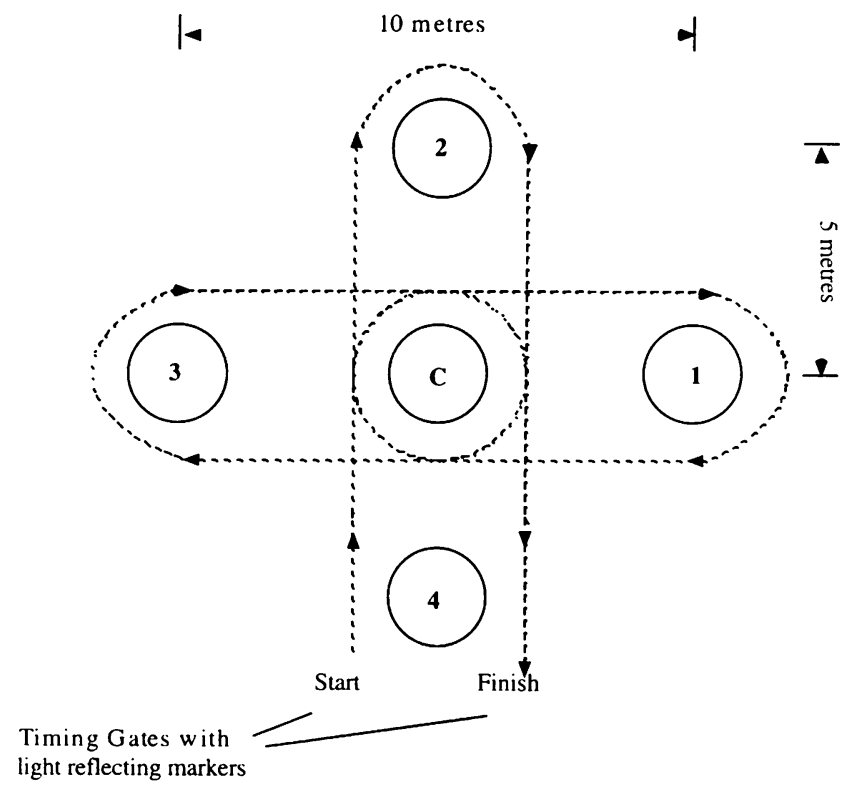

Figure 1. The agility run. Players ran from the start, turned right at the centre cone $(C)$, ran round cone 1 , back to $C$, around cone 2 , back to $C$, around cone 3 , back to $C$, and out to the finish

(3) To assess a player's agility and turning ability, an agility run was performed (see Figure 1). The time taken to complete the agility drill with the player turning to the right was recorded.

(4) Push-ups at a constant cadence were then performed as a test of upper body muscular endurance. Push-up position was standardised by having the subjects lie prone with their arms abducted to shoulder level (crucifix position). From this position their elbow joints were flexed to 90 degrees, and the elbows were drawn backward so that the hands could be placed on the floor, directly below the elbows when viewed from above. A cadence of 50 beats per minute was played over an audio cassette, with the subject keeping in time with the tone so that their elbows were fully extended for one beat and flexed to 90 degrees for the next beat. Successful repetitions were counted and recorded until the subject could no longer keep pace with the cadence. (5) 30-metre sprint times from a standing start and from a 5 metre running start were recorded. Times were measured electronically using a digital timer (Lafayette) and a set of light reflecting switches. The momentum the player obtained during the sprint from a standing start was calculated according to the following formula (Handcock PJ, Rietjens GJ, unpublished):

$\frac{\text { Time taken for sprint from standing start }(\mathrm{s})}{30 \mathrm{~m} \times \text { Player's body mass }(\mathrm{kg})}$

(6) The final physical assessment was a set of six repeated high intensity shuttles. Modified from the repeated high intensity endurance test, ${ }^{23}$ this test is designed to measure the anaerobic endurance, or "recoverability" of the players. Each repetition of the test consists of sprinting a distance of $70 \mathrm{~m}$. The players run out to a 5 metre mark and back to the start, out to 
Table 2. RIPP cohort pre-season 1993. Anthropometric characteristics of male players

\begin{tabular}{|c|c|c|c|c|c|c|c|c|c|c|c|c|c|}
\hline & & \multicolumn{8}{|c|}{ Grade } & \multirow[b]{2}{*}{ RMSE* } & \multirow[b]{2}{*}{$P$ (grade)t } & \multirow[b]{2}{*}{$P($ position $) t$} & \multirow[b]{2}{*}{$E S$ (position) $\neq$} \\
\hline & & \multicolumn{2}{|c|}{ Senior $A$} & \multicolumn{2}{|c|}{ Senior B } & \multicolumn{2}{|c|}{ Under-21 } & \multicolumn{2}{|c|}{ Under-19/18 } & & & & \\
\hline & & $\mathrm{n}$ & & $\mathrm{n}$ & & $\mathrm{n}$ & & $\mathrm{n}$ & & & & & \\
\hline \multirow[t]{2}{*}{ Age (years) } & Forwards & 50 & 22.7 & 20 & 25.5 & 33 & 18.9 & 29 & 16.7 & & & & \\
\hline & Backs & 44 & 21.9 & 19 & 22.5 & 32 & 18.9 & 25 & 17.1 & & & & \\
\hline \multirow[t]{2}{*}{ Height $(\mathrm{cm})$} & Forwards & 50 & 186.0 & 20 & 181.2 & 33 & 183.3 & 29 & 180.2 & 6.02 & 0.001 & 0.001 & 1.0 \\
\hline & Backs & 44 & 177.8 & 19 & 176.5 & 32 & 177.5 & 25 & 175.4 & & & & \\
\hline \multirow[t]{2}{*}{ Mass $(\mathrm{kg}) \S$} & Forwards & 50 & 98.5 & 20 & 88.1 & 33 & 89.4 & 29 & 82.6 & $\log 0.11$ & 0.001 & 0.001 & 1.3 \\
\hline & Backs & 44 & 81.8 & 19 & 77.3 & 32 & 75.5 & 25 & 72.0 & & & & \\
\hline \multirow{2}{*}{$\begin{array}{l}\text { Neck } \\
\text { circumference } \\
\text { (cm) }\end{array}$} & Forwards & 47 & 42.7 & 19 & 40.3 & 33 & 40.8 & 29 & 39.3 & 1.88 & 0.001 & 0.001 & 1.1 \\
\hline & Backs & 39 & 39.6 & 19 & 38.6 & 32 & 38.6 & 25 & 37.6 & & & & \\
\hline \multirow[t]{2}{*}{ Endomorphy§ } & Forwards & 47 & 3.7 & 19 & 3.2 & 33 & 3.6 & 28 & 3.4 & $\log 0.32$ & 0.235 & 0.001 & 1.0 \\
\hline & Backs & 41 & 2.5 & 19 & 2.9 & 32 & 2.4 & 25 & 2.2 & & & & \\
\hline \multirow[t]{2}{*}{ Mesomorphy§ } & Forwards & 47 & 6.5 & 18 & 6.0 & 33 & 5.9 & 25 & 5.6 & $\log 0.18$ & 0.001 & 0.017 & 0.3 \\
\hline & Backs & 39 & 6.2 & 17 & 5.3 & 32 & 5.4 & 23 & 5.5 & & & & \\
\hline \multirow[t]{2}{*}{ Ectomorphy } & Forwards & 50 & 1.1 & 19 & 1.4 & 33 & 1.5 & 28 & 2.0 & 0.80 & 0.001 & 0.001 & 0.5 \\
\hline & Backs & 44 & 1.4 & 19 & 1.8 & 32 & 2.2 & 25 & 2.3 & & & & \\
\hline
\end{tabular}

* Root mean square error - an unbiased estimate of the sample standard deviation

+ All $P$ values are less than or equal to the reported value

\# Effect size between positions: (mean of forwards minus mean of backs)/RMSE

$\S$ Log transformations were used for the analysis, so geometric means are reported

a 10 metre mark and back to the start, and then out to a 20 metre mark and back to the start. Repetitions bagan every $30 \mathrm{~s}$. Following each repetition, the subjects were allowed to recover for the remainder of the $30 \mathrm{~s}$ period. The time taken to complete each shuttle was recorded. A "fatigue index" for each player was calculated as follows:

Fatigue index $=$ Average repetition

$$
\begin{aligned}
& \times(\text { slowest repetition }- \text { fastest repetition }) \\
& \times \frac{6}{\text { Repetitions completed }}
\end{aligned}
$$

The players who were unable to complete all six repetitions were penalised by multiplying their score by six (the maximum possible number of shuttles) and dividing by the number they completed.

The schoolgirls were unable to complete the vertical jump, the push ups, and the anaerobic shuttle test, due to a lack of available time at the testing facility.

\section{Analyses}

The analyses for the male and female players were performed separately. Summary statistics were calculated by grade and positional category for the anthropometric and physical performance measures. Preliminary examination of the data revealed that some of these measures were not normally distributed. To normalise the data, log transformations were performed upon the following variables (for the males only): weight, endomorphy, mesomorphy, both conditions of the 30-metre sprints, and the fatigue index.

A series of analyses of variance (ANOVA) was used to examine differences between positions and grades. An interaction term between grade and position was included in the models. A significant interaction term indicates that the pattern of differences observed between forwards and backs varies between the grades. A Bonferroni adjustment was made to correct for multiple testing. Differences between groups were accepted as statistically significant at the 0.05 level if the $P$ value was $<0.002(0.05 / 21)$. Post-hoc Scheffé tests were performed on the anthropometric variables, the aerobic shuttle, the 30-metre sprint from a standing start, and momentum. These were done to further examine the differences between the following pairs of grades: senior $A$ and senior $B$; senior $A$ and under-21; and under-21 and under-19/18. In addition to testing for significant differences between group means, the effect size (ES) was calculated by taking the difference between the group means, and dividing by the root mean square error (RMSE). The effect size is considered to provide an indication of the "meaningfulness" of differences. Following the guidelines presented by Cohen, ${ }^{24}$ an effect size of 0.2 is considered "small", 0.5 is considered "medium", and 0.8 is considered "large". The RMSE is used as an unbiased estimate of the sample standard deviation. The SYSTAT ${ }^{25}$ computer package was used for the statistical analyses.

\section{Results \\ Males}

The anthropometric characteristics of the males are summarised in Table 2. Forwards were on average $6 \mathrm{~cm}$ taller and $14 \mathrm{~kg}$ heavier than backs. In terms of somatotype, the forwards were significantly more endomorphic and less ectomorphic than backs. The positions did not differ significantly in terms of mesomorphy ( $E S=0.3$ ).

Significant differences in the anthropometric charac- 
Anthropometry and physical performance in rugby: K L Quarrie et al.

Table 3. RIPP cohort pre-season 1993. Physical performance characteristics of male players

\begin{tabular}{|c|c|c|c|c|c|c|c|c|c|c|c|c|c|c|}
\hline & & \multicolumn{8}{|c|}{ Grade } & \multirow{2}{*}{\multicolumn{2}{|c|}{ RMSE }} & \multirow[b]{2}{*}{$P(\text { grade })^{*}$} & \multirow[b]{2}{*}{$P{\text { (position })^{*}}$} & \multirow[b]{2}{*}{ ES (position)t } \\
\hline & & \multicolumn{2}{|c|}{ Senior A } & \multicolumn{2}{|c|}{ Senior $B$} & \multicolumn{2}{|c|}{ Under-21 } & \multicolumn{2}{|c|}{ Under-19/18 } & & & & & \\
\hline & & $n$ & & $n$ & & $n$ & & $n$ & & & & & & \\
\hline \multirow{2}{*}{$\begin{array}{l}\text { Aerobic } \\
\text { shuttle (No) }\end{array}$} & Forwards & 50 & 108.6 & 19 & 114.3 & 32 & 104.6 & 29 & 100.2 & & 17.5 & 0.001 & 0.001 & 0.5 \\
\hline & Backs & 43 & 127.4 & 19 & 115.2 & 29 & 118.4 & 24 & 105.0 & & & & & \\
\hline \multirow{2}{*}{$\begin{array}{l}\text { Vertical } \\
\text { jump (cm) }\end{array}$} & Forwards & 50 & 59.7 & 17 & 55.2 & 32 & 58.4 & 29 & 56.8 & & 7.51 & 0.09 & 0.001 & 0.6 \\
\hline & Backs & 44 & 63.2 & 18 & 60.3 & 29 & 61.8 & 24 & 62.9 & & & & & \\
\hline \multirow[t]{2}{*}{ Push-ups (No) } & Forwards & 44 & 25.6 & 18 & 26.6 & 33 & 22.1 & 28 & 24.5 & & 7.43 & 0.001 & 0.001 & 0.5 \\
\hline & Backs & 36 & 32.3 & 19 & 29.2 & 29 & 27.3 & 24 & 24.9 & & & & & \\
\hline \multirow{2}{*}{$\begin{array}{l}\text { Agility run } \\
\text { (s) }\end{array}$} & Forwards & 50 & 12.2 & 18 & 12.4 & 33 & 12.3 & 29 & 12.2 & & 0.58 & 0.039 & 0.001 & 0.8 \\
\hline & Backs & 42 & 11.5 & 19 & 11.9 & 29 & 11.9 & 24 & 12.0 & & & & & \\
\hline \multirow{2}{*}{$\begin{array}{l}30 \text { m sprint } \\
\text { standing } \\
\text { start }(s) \neq\end{array}$} & Forwards & 45 & 4.5 & 12 & 4.8 & 33 & 4.5 & 29 & 4.6 & $\log$ & 0.05 & 0.001 & 0.001 & 1.1 \\
\hline & Backs & 37 & 4.3 & 12 & 4.5 & 29 & 4.4 & 24 & 4.4 & & & & & \\
\hline \multirow{2}{*}{$\begin{array}{r}\text { Momentum } \\
\left(\mathrm{kg} \cdot \mathrm{m} \cdot \mathrm{s}^{-1}\right)\end{array}$} & Forwards & 45 & 654 & 12 & 570 & 33 & 603 & 29 & 535 & & 70.5 & 0.001 & 0.001 & 0.9 \\
\hline & Backs & 37 & 573 & 12 & 530 & 29 & 522 & 24 & 496 & & & & & \\
\hline \multirow{2}{*}{$\begin{array}{l}30 \mathrm{~m} \text { sprint } \\
\text { running } \\
\text { start }(\mathrm{s}) \neq\end{array}$} & Forwards & 45 & 4.0 & 12 & 4.1 & 33 & 4.0 & 28 & 4.1 & $\log$ & 0.05 & 0.001 & 0.001 & 1.1 \\
\hline & Backs & 37 & 3.7 & 12 & 3.9 & 29 & 3.8 & 24 & 3.9 & & & & & \\
\hline \multirow[t]{2}{*}{ Fatigue index $\neq$} & Forwards & 49 & 49.0 & 18 & 55.9 & 32 & 57.7 & 28 & 56.8 & $\log$ & 0.24 & 0.001 & 0.115 & 0.44 \\
\hline & Backs & 41 & 47.9 & 19 & 68.3 & 28 & 59.7 & 23 & 70.2 & & & & & \\
\hline
\end{tabular}

* All $P$ values are less than or equal to the reported value

+ Effect size between positions

₹ Log transformations were done for these variables, so geometric means are reported

$\mathrm{RMSE}=$ root mean square error

Table 4. RIPP cohort preseason 1993. Anthropometric characteristics of female rugby players by position and grade

\begin{tabular}{|c|c|c|c|c|c|c|c|c|c|}
\hline & & \multicolumn{4}{|c|}{ Grade } & \multirow[b]{2}{*}{ RMSE } & \multirow[b]{2}{*}{$P(\text { grade })^{*}$} & \multirow[b]{2}{*}{$P{\text { (position })^{*}}^{*}$} & \multirow[b]{2}{*}{ ES (position)t } \\
\hline & & \multicolumn{2}{|c|}{ Seniors } & \multicolumn{2}{|c|}{ Schoolgirls } & & & & \\
\hline & & $\mathrm{n}$ & & $\mathrm{n}$ & & & & & \\
\hline \multirow[t]{2}{*}{ Age (years) } & Forwards & 35 & 21.6 & 13 & 16.0 & & & & \\
\hline & Backs & 31 & 20.4 & 12 & 15.8 & & & & \\
\hline \multirow[t]{2}{*}{ Height $(\mathrm{cm})$} & Forwards & 35 & 166.7 & 13 & 166.2 & 6.10 & 0.065 & 0.002 & 0.8 \\
\hline & Backs & 31 & 164.1 & 12 & 159.1 & & & & \\
\hline \multirow[t]{2}{*}{ Mass (kg) } & Forwards & 35 & 75.6 & 13 & 67.3 & 8.80 & 0.001 & 0.001 & 1.5 \\
\hline & Backs & 31 & 61.4 & 12 & 55.1 & & & & \\
\hline \multirow[t]{2}{*}{ Neck (cm) } & Forwards & 34 & 34.9 & 13 & 33.2 & 1.70 & 0.001 & 0.001 & 1.2 \\
\hline & Backs & 30 & 32.7 & 10 & 31.5 & & & & \\
\hline \multirow[t]{2}{*}{ Endomorphy } & Forwards & 35 & 5.1 & 13 & 4.8 & 1.12 & 0.504 & 0.001 & 1.2 \\
\hline & Backs & 30 & 3.6 & 12 & 3.5 & & & & \\
\hline \multirow[t]{2}{*}{ Mesomorphy } & Forwards & 34 & 5.9 & 13 & 4.7 & 1.28 & 0.046 & 0.001 & 0.8 \\
\hline & Backs & 30 & 4.3 & 10 & 4.2 & & & & \\
\hline \multirow[t]{2}{*}{ Ectomorphy } & Forwards & 35 & 0.9 & 13 & 1.6 & 0.80 & 0.030 & 0.001 & 1.0 \\
\hline & Backs & 31 & 1.9 & 12 & 2.1 & & & & \\
\hline
\end{tabular}

* All $P$ values are less than or equal to the reported value

+ Effect size between positions

RMSE = root mean square error

teristics of players were also apparent when the various grades were compared. The senior A players were significantly taller, heavier, more mesomorphic, and possessed larger necks than the senior B players. The effect sizes for these comparisons ranged from 0.5 to 0.9 . Comparisons between senior $A$ and under-21 players showed that senior A players were significantly heavier, more mesomorphic, less ectomorphic, and possessed larger neck circumferences, with effect sizes ranging from $0.7-0.9$. The under-21 players were significantly heavier and had larger neck circumferences than the under-19/18s (ES $=0.6$ in both cases). The only anthropometric variable on which there was not a significant difference across grades was endomorphy.

The results for the male physical performance assessments are presented in Table 3. The backs performed significantly better than the forwards on all the physical performance activities except the fatigue index and the momentum obtained during the sprint. Large effect sizes $(\geqslant 0.8)$ were observed between the positions for the agility run, the sprints from both a standing and running start, and momentum. The effect 
Table 5. RIPP cohort preseason 1993. Physical performance characteristics of female rugby players

\begin{tabular}{|c|c|c|c|c|c|c|c|c|c|}
\hline & & \multicolumn{4}{|c|}{ Grade } & \multirow[b]{2}{*}{ RMSE } & \multirow[b]{2}{*}{$P(\text { grade })^{*}$} & \multirow[b]{2}{*}{$P(\text { position })^{*}$} & \multirow[b]{2}{*}{ ES (position)t } \\
\hline & & \multicolumn{2}{|c|}{ Seniors } & \multicolumn{2}{|c|}{ Schoolgirls } & & & & \\
\hline & & $\mathrm{n}$ & & $\mathrm{n}$ & & & & & \\
\hline Aerobic & Forwards & 35 & 65.9 & 13 & 49.8 & 17.38 & 0.001 & 0.002 & 0.8 \\
\hline shuttle (No) & Backs & 31 & 85.6 & 10 & 57.9 & & & & \\
\hline $\begin{array}{l}\text { Agility } \\
\text { run (s) }\end{array}$ & $\begin{array}{l}\text { Forwards } \\
\text { Backs }\end{array}$ & $\begin{array}{l}35 \\
31\end{array}$ & $\begin{array}{l}13.3 \\
12.8\end{array}$ & $\begin{array}{l}13 \\
10\end{array}$ & $\begin{array}{l}13.3 \\
13.1\end{array}$ & 0.800 & 0.361 & 0.072 & 0.5 \\
\hline $\begin{array}{l}\text { Vertical } \\
\text { jump }(\mathrm{cm})\end{array}$ & $\begin{array}{l}\text { Forwards } \\
\text { Backs }\end{array}$ & $\begin{array}{l}35 \\
31\end{array}$ & $\begin{array}{l}39.6 \\
44.8\end{array}$ & & & 5.60 & & 0.001 & 0.9 \\
\hline Push-ups (No) & $\begin{array}{l}\text { Forwards } \\
\text { Backs }\end{array}$ & $\begin{array}{l}35 \\
31\end{array}$ & $\begin{array}{l}12.1 \\
16.4\end{array}$ & & & 8.30 & & 0.042 & 0.5 \\
\hline $\begin{array}{l}30 \mathrm{~m} \text { sprint } \\
\text { standing start (s) }\end{array}$ & $\begin{array}{l}\text { Forwards } \\
\text { Backs }\end{array}$ & $\begin{array}{l}35 \\
31\end{array}$ & $\begin{array}{l}5.3 \\
5.0\end{array}$ & $\begin{array}{l}13 \\
10\end{array}$ & $\begin{array}{l}5.2 \\
5.1\end{array}$ & 0.31 & 0.972 & 0.005 & 0.6 \\
\hline $\begin{array}{l}\text { Momentum } \\
\left(\mathrm{kg} \cdot \mathrm{m} \cdot \mathrm{s}^{-1}\right)\end{array}$ & $\begin{array}{l}\text { Forwards } \\
\text { Backs }\end{array}$ & $\begin{array}{l}34 \\
31\end{array}$ & $\begin{array}{l}428 \\
368\end{array}$ & $\begin{array}{l}13 \\
10\end{array}$ & $\begin{array}{l}385 \\
327\end{array}$ & 53 & 0.002 & 0.001 & 1.1 \\
\hline $\begin{array}{l}30 \mathrm{~m} \text { sprint } \\
\text { running start (s) }\end{array}$ & $\begin{array}{l}\text { Forwards } \\
\text { Backs }\end{array}$ & $\begin{array}{l}35 \\
31\end{array}$ & $\begin{array}{l}4.8 \\
4.4\end{array}$ & $\begin{array}{l}13 \\
10\end{array}$ & $\begin{array}{l}4.8 \\
4.6\end{array}$ & 0.32 & 0.425 & 0.001 & 0.9 \\
\hline Fatigue index & $\begin{array}{l}\text { Forwards } \\
\text { Backs }\end{array}$ & $\begin{array}{l}22 \\
26\end{array}$ & $\begin{array}{r}130.1 \\
89.8\end{array}$ & & & 76.28 & & 0.043 & 0.5 \\
\hline
\end{tabular}

* All $P$ values are less than or equal to the reported value

+ Effect size between positions

RMSE = root mean square error

sizes for the aerobic shuttle, the vertical jump, and the pushups were moderate $(0.5-0.6)$.

Differences between grades reached statistical significance for the aerobic shuttle, the push-ups, the sprints (both conditions), and the momentum obtained by the players. The post-hoc comparisons between the grades showed that the senior As performed significantly better than the senior Bs on the 30-metre sprint from a standing start, on the fatigue index, and on the measure of momentum ( $E S=1.0$ for all). The senior A players obtained greater momentum during the sprint than the under-21 players $(E S=0.7)$, and the under- 21 players obtained greater momentum during the sprint than the under-19/18 players $(E S=0.7)$. The senior A players also performed better than the under-21 players on the fatigue index $(E S=0.8)$.

\section{Females}

As was the case with the men, there were large differences between the anthropometric characteristics of the female forwards and backs (see Table 4). The forwards were on average $5 \mathrm{~cm}$ taller and $13 \mathrm{~kg}$ heavier than the backs. They also possessed larger neck circumferences and were more endo-mesomorphic and less ectomorphic than backs.

In terms of the physical assessments, the backs generally performed better than the forwards. A summary of the physical performance assessments, and the effect sizes between the positions is shown in Table 5 . The differences between the positions were large on the aerobic shuttle test, the vertical jump, the sprint from a rolling start, and momentum. The only assessment in which the female forwards performed better than the backs was for the momentum obtained.

Of the tests completed by both the Senior Women and the Schoolgirls, the aerobic shuttle was the only one on which large differences in performance were observed $(\mathrm{ES}=1.3)$.

\section{Discussion}

A large number of players was enrolled in this study, providing an opportunity to present a more comprehensive description of players from various grades than has been reported before. The body contact nature of rugby appears to demand specific anthropometric and physical performance characteristics from players. The results indicated that forwards (both males and females) were taller, possessed greater body mass, and had larger neck circumferences than backs. As might be expected when examining differences between grades that were defined primarily by age (below the senior level), the players in the higher grades generally possessed larger physiques.

In contrast to the patterns observed by Rigg and Reilly, ${ }^{8}$ but consistent with the findings of several other anthropometric studies, ${ }^{2,3,5}$ the somatotypes of the forwards in the current study were more endomesomorphic than those of the backs. As endomesomorphs have been shown to be stronger than either mesomorphs or ecto-mesomorphs, ${ }^{26}$ this may reflect the greater demands for strength placed on forwards during scrummaging, rucking, and mauling.

The anthropometric characteristics of New Zealand senior A club players are similar to those of senior club and international players in England, Italy, and South Africa, 3, 5, 6, 9 (see Table 1). New Zealand senior women forwards in the present study possess greater body mass than those described in other studies of women forwards. ${ }^{12-14}$ The female backs do, however, closely match the heights, body mass, and somatotypes of English senior backs and American college backs. ${ }^{12,13}$ 
As the game of rugby demands a variety of fitness attributes from players, the test items selected for this study were designed to assess "rugby fitness" components. Because many of the tests are adapted specifically for rugby, the opportunity for comparisons with other studies are limited. The results show that backs perform significantly better than forwards on most of the physical performance assessments. Taken at face value this would lead to the conclusion that the backs are fitter, even in tests previously considered to favour forwards (such as push-ups). The influence of body mass on player performance in all tests must be considered, however, when attempting to draw conclusions between the positional groups. This is apparent when the momentum obtained by the players during the sprints is examined. The forwards are capable of producing greater momentum than backs from the same grade, and players at higher grades are capable of producing greater momentum than players at lower grades. As momentum is a vector quantity, if two players moving in opposite directions at velocities of equal magnitude collide the change in their respective velocities will be inversely proportional to their masses. ${ }^{27}$ Although the total momentum of both players before and after the impact remains the same, after the impact they will tend to move in the direction in which the player with greater mass was travelling before the impact. Thus the greater momentum that players with higher body mass can obtain is a definite advantage, especially in body contact situations such as tackles, and play associated with scrums, rucks, and mauls.

The senior B forwards performed, on average, slightly better than the senior A forwards on the aerobic assessment. It appears that, although aerobic fitness and speed are important for rugby players, ${ }^{28}$ forwards are prepared to compromise these aspects of fitness to some extent in order to maintain a higher body mass.

The fatigue index was designed to examine the ability of players to recover from bursts of high intensity exercise. Further work should be undertaken to help clarify the importance of this type of fitness to rugby performance, and its relation to other factors important to performance in the game.

Holmyard and Hazeldine 9 noted greater differences between positional categories at higher levels of play. Although not reaching significance, some of the current results are consistent with this pattern. For example, the senior B forwards and backs tend to be more homogeneous in terms of endomorphy and performance on the aerobic shuttle test than were the forwards and backs at other grades. Presumably, the positional requirements for specific anthropometric and fitness attributes are less stringent at the senior $B$ level than at senior $A$. The senior $B$ players are often a mix of those who did not possess the requisite skills or anthropometric characteristics to make senior $A$ teams and older players who drop down a grade when they find the pace in the senior A grade difficult to maintain.

The current findings concur with previous work which indicates that rugby forwards and backs possess different anthropometric and physical performance attributes, and that these different attributes reflect the demands placed upon them in terms of the performance requirements of the sport. Differences are also apparent between the various grades for typical anthropometric and physical performance characteristics. The ability to obtain the greater momentum that a higher body mass enables may be an important attribute required for play in the forward positions.

\section{Acknowledgements}

The rugby injury and performance project is funded by a grant from the Accident Rehabilitation and Compensation Insurance Corporation (ACC). The Injury Prevention Research Unit is jointly funded by the Health Research Council of New Zealand and the ACC. The views expressed in this paper are those of the authors and do not necessarily reflect those of the above organisations. The authors wish to thank the following people: the RIPP cohort members: Ms Sheila Williams and Mr Stephen Marshall for statistical advice; Ms Yvonne Bird. We also wish to acknowledge the support and assistance of the Otago Rugby Football Union and the New Zealand Rugby Football Union.

\section{References}

1 Withers RT, Craig NP, Norton KI. Somatotypes of South Australian male athletes. Hum Biol 1986; 58 : 337-56.

2 Boennec P, Prevost M, Ginet L. Somatotype de sportif de haut niveau. Resultats dans huit disciplines differentes. Medecine $d u$ Sport 1980; 54: 309-18.

3 Casagrande G, Viviani F. Somatotype of Italian rugby players. J Sports Med Phys Fitness 1993; 33: 65-9.

4 Ueno $Y$, Watai E, Ishii K. Aerobic and anaerobic power of rugby football players. In: Reilly T, Lees A, Davids K, Murphy WJ, eds. Science and football. London: E and FN Spon, 1987.

5 Smit PJ, Daehne HO, Burger E. Somatotypes of South African rugby players. In: Smit PJ, ed. Sport and somatology in ischaemic heart disease. Pretoria: University of Pretoria, 1979.

6 Jardine MA, Wiggins TM, Myburgh KH, Noakes TD. Physiological characteristics of rugby players including muscle glycogen content and muscle fibre composition. $S$ Afr Med J 1988; 73: 529-32.

7 Reilly T, Hardiker R. Somatotype and injuries in adult student rugby football. J Sports Med Phys Fitness 1981; 21 : 186-91.

8 Rigg P, Reilly T. A fitness profile and anthropometric analysis of first and second class rugby union players. In: Reilly T, Lees A, Davids K, Murphy WJ, eds. Science and football. London: E and FN Spon, 1987.

9 Holmyard DJ, Hazeldine RJ. Seasonal variations in the anthropometric and physiological characteristics of international rugby union players. In: Reilly T, Clarys JP, Stibbe A, eds. Science and football II: proceedings of the Second World Congress of Science and Football, Eindhoven, The Netherlands. London: E and FN Spon, 1993.

10 Maud PJ. Physiological and anthropometric parameters that describe a rugby union team. Br J Sports Med 1983; 17: 16-23.

11 Maud PJ, Shultz BB. The US National Rugby Team: a physiological and anthropometric assessment. Physician Sportsmed 1984; 12: 86-94.

12 Kirby WJ, Reilly T. Anthropometric and fitness profiles of elite female rugby union players. In: Reilly T, Clarys JP, Stibbe A, eds. Science and football II: proceedings of the Second World Congress of Science and Football, Eindhoven, The Netherlands. London: E and FN Spon, 1993.

13 Williams KM. Size, somatotypes and skinfold patterns of women rugby players. San Diego: San Diego State University, 1984 [Master's Thesis].

14 Sedlock DA, Fitzgerald PI, Knowlton RG. Body composition and performance characteristics of collegiate women rugby players. Res $Q$ Exerc Sport 1988; 59: 78-82.

15 Watson AW. Discriminant analysis of the physiques of schoolboy rugby players, hurlers and non-team members. J Sports Sci 1988; 6: $131-40$. 
16 Docherty D, Wenger HA, Neary P. Time-motion analysis related to the physiological demands of rugby. J Hum Movement Stud 1988; 14: 269-77.

17 McLean DA. Analysis of the physical demands of international rugby union. I Sports Sci 1992; 10: 285-96.

18 Cheetham ME, Hazeldine RJ, Robinson A, Williams C. Power output of rugby forwards during maximal treadmill sprinting. In Reilly T, Lees A, Davids K, Murphy WJ, eds. Science and football. London: E and FN Spon, 1987.

19 Waller AE, Feehan M, Marshall S, Chalmers DJ. The New Zealand Rugby Injury and Performance Project. I. Design and Methodology of a Prospective Follow-up Study. The Br J Sports Med 1994; 28 : 223-8.

20 Carter JEL, Heath BH. Somatotyping - development and applications. In: Lasker GW, Mascie-Taylor CGN, Roberts DF, eds. Cambridge studies in biological anthropology. Cambridge: Cambridge University Press, 1990.
21 Leger LA, Lambert J. A maximal multi-stage 20-m shuttle run test to predict VO,max. Eur J Appl Physiol 1982; 49: 1-12.

22 Leelarthaepin B. Assessment of physical fitness - a practical approach Sydney: Leelar Biomedical Services, 1985.

23 Smith DJ. Physiological and performance components of endurance. Edmonton: University of Alberta, 1981 [PhD Thesis].

24 Cohen J. Statistical power analysis for the behavioral sciences. (Revised ed). New York: Academic Press, 1977.

25 Wilkinson L, Hill M, Vang E. SYSTAT for the Macintosh, Version 5.2. 1992. Evanston, Illinois: SYSTAT Inc.

26 Bale P, Colley E, Mayhew J. Size and somatotype correlates of strength and physiological performance in adult male students. Aust J Sci Med Sport 1984; 16: 2-6.

27 Enoka RM. Neuromechanical basis of kinesiology. Champaign Illinois: Human Kinetics Publishers, 1988

28 Handcock P. Physical preparation for rugby union. J Phys Educ NZ 1993; 26 : 7-9.

\section{Royal Society of Medicine Sports Medicine Meetings 1995-6}

These meetings are all held at $5.30 \mathrm{pm}$ at 1 Wimpole St London W1. Non-members can be guests of a member. The meetings are free of charge but a buffet supper with wine follows the meeting at a cost of $£ 11.00$. Further details from Alyson Taylor, Academic Office, tel 0171-290-2985.

Thursday December 14th 1995:

\begin{tabular}{ll} 
Myperbarbarism & \multicolumn{1}{c}{ Management of life threatening conditions } \\
Drowning & Prof David Elliott \\
$\begin{array}{ll}\text { Cardiac arrest } & \text { Dr Mark Harries } \\
\text { Hyperthermia and EAC (exercise associ- } & \text { Dr Robin Northcote } \\
\text { ated collapse) } & \text { Dr Dan Tunstall Pedoe }\end{array}$
\end{tabular}

Thursday January 18th 1996 :

$\begin{array}{ll}\text { Physiologically } & \text { Dr Bruce Davies } \\ \text { Nutritionally } & \text { Prof Clyde Williams } \\ \text { Psychologically } & \text { Dr Lew Hardy } \\ \text { The response of the athlete } & \text { Dr Richard Budgett }\end{array}$

Thursday March 21st 1996 (joint meeting with Section of Neurology):

\section{Neurological Disorders in Sport}

Peripheral nerve injury associated with Mr Rolfe Birch intense physical training

Athletic activity and epilepsy Dr Simon Shorvorn

Athletic performance as therapy Dr Fred Middleton

Thursday 16th May 1996: Annual General Meeting

Sport and the Law (Speakers to be confirmed)

GBH: Responsibility for injury, The responsibilities of the club doctor, The

Athlete's rights.

Thursday 20th June 1996:

Health benefits and dangers of exercise 


\section{Corrections}

In the paper by Quarrie et al in the December issue (volume 29, pages263-270) there were two uncorrected errors:

On page 264, right column, line 7, the sentence should read: "First class locks and loose forwards performed significantly better than did theirrespective second class peers on a vertical jump test."

On page 265 , right column the formula for momentum has been inverted. It should be as follows:

$30 \mathrm{~m}$

Time taken for sprint from standing start(s)

Player's body mass $(\mathrm{kg})$

In the paper by Cattermole et al in the June issue (The footballer's fracture; vol 30, pp 171-175), table 5 was accidentally omitted and the table labelled 5 should have been number 6 . The omitted table is reproduced here.

Table 5 AO/ASIF classifications

\begin{tabular}{|c|c|}
\hline AOIASIF classification & Number \\
\hline $\begin{array}{l}42 \text { A } 1.1 \\
42 \text { A } 1.2 \\
42 \text { A } 1.3\end{array}$ & $\begin{array}{l}3 \\
1 \\
1\end{array}$ \\
\hline $\begin{array}{l}42 \text { А } 2.1 \\
42 \text { А } 2.2 \\
42 \text { А } 2.3\end{array}$ & $\begin{array}{l}5 \\
2 \\
4\end{array}$ \\
\hline $\begin{array}{l}42 \text { A } 3.1 \\
42 \text { A } 3.2 \\
42 \text { A } 3.3\end{array}$ & $\begin{array}{l}25 \\
2 \\
31\end{array}$ \\
\hline $\begin{array}{l}42 \text { В } 1.1 \\
42 \text { В } 1.2 \\
42 \text { В } 1.3\end{array}$ & $\begin{array}{l}1 \\
1 \\
0\end{array}$ \\
\hline $\begin{array}{lll}42 & \text { В } 2.1 \\
42 & \text { В } 2.2 \\
42 & \text { В } 2.3\end{array}$ & $\begin{array}{l}0 \\
1 \\
2\end{array}$ \\
\hline $\begin{array}{l}42 \text { В } 3.1 \\
42 \text { В } 3.2 \\
42 \text { В } 3.3\end{array}$ & $\begin{array}{l}5 \\
1 \\
12\end{array}$ \\
\hline $\begin{array}{llll}42 & C & 1.1 \\
42 & C & 1.2 \\
42 & C & 1.3\end{array}$ & $\begin{array}{l}0 \\
0 \\
2\end{array}$ \\
\hline $\begin{array}{lll}42 & C & 2.1 \\
42 & C & 2.2 \\
42 & C & 2.3\end{array}$ & $\begin{array}{l}0 \\
0 \\
0\end{array}$ \\
\hline $\begin{array}{lll}42 & C & 3.1 \\
42 & C & 3.2 \\
42 & C & 3.3\end{array}$ & $\begin{array}{l}0 \\
1 \\
0\end{array}$ \\
\hline Total & 100 \\
\hline
\end{tabular}

